\title{
3 Research Square

\section{"...the availability of contraceptives is everywhere.": Coordinated Family Planning Service Delivery in Rwanda Facilitates Integration into Other Health Services}

\section{Adriana Scanteianu}

Rutgers The State University of New Jersey

Hilary M Schwandt ( $\sim$ hschwand@jhsph.edu )

Western Washington University https://orcid.org/0000-0003-3959-9594

Angel Boulware

Spelman College

Julia Corey

Wheaton College

Ana Herrera

Northwest Vista Community College

Ethan Hudler

Whatcom Community College

Claudette Imbabazi

INES

llia King

Xavier University

Jessica Linus

University of Maryland Baltimore County

Innocent Manzi

INES

Maddie Merritt

Western Washington University

Lyn Mezier

State University of New York at Oswego

Abigail Miller

Western Washington University

Haley Morris

Western Oregon University

Dieudonne Musemakweli

INES 


\section{Uwase Musekura}

Eastern Oregon University

\section{Divine Mutuyimana}

INES

\section{Chimene Ntakarutimana}

University of Kentucky

\section{Nirali Patel}

Arcadia University

\section{Biganette-Evidente Shemeza}

INES

\section{Madi Stapleton}

Western Washington University

\section{Gi'anna Sterling-Donaldson}

Drexel University

Chantal Umutoni

INES

Lyse Uwera

INES

\section{Madeleine Zeiler \\ Western Washington University \\ Seth Feinberg \\ Western Washington University}

\section{Research article}

Keywords: Rwanda, family planning, integration, community health worker, coordinated services

Posted Date: July 16th, 2019

DOl: https://doi.org/10.21203/rs.2.11427/v1

License: (c) (i) This work is licensed under a Creative Commons Attribution 4.0 International License. Read Full License 


\section{Abstract}

Background High fertility rates pose health risks to both mothers and children and impede economic growth; therefore, family planning use is vital to achieving sustainable population growth and to help build thriving communities. Contraceptive use in Rwanda has tripled since 2005. This study aims to understand the role of coordinated and integrated family planning service delivery in achieving this unparalleled success in Rwanda. Methods This qualitative study in 2018 included eight focus group discussions with family planning providers and 32 in-depth interviews with experienced family planning users. Results Results indicate a well-coordinated family planning service delivery system with community health workers and nurses filling different and complementary roles in meeting family planning client needs at the local level. In addition, integration of family planning into other maternal and child health services is the norm. Conclusions The coordination and integration of family planning across both providers and services may help explain the extraordinary increase in Rwanda's contraceptive usage, and has potential applications for enhancing family planning service delivery in other settings as well.

\section{Abstract}

\section{Background}

High fertility rates pose health risks to both mothers and children and impede economic growth; therefore, family planning use is vital to achieving sustainable population growth and to help build thriving communities. Contraceptive use in Rwanda has tripled since 2005. This study aims to understand the role of coordinated and integrated family planning service delivery in achieving this unparalleled success in Rwanda.

\section{Methods}

This qualitative study in 2018 included eight focus group discussions with family planning providers and 32 in-depth interviews with experienced family planning users.

\section{Results}

Results indicate a well-coordinated family planning service delivery system with community health workers and nurses filling different and complementary roles in meeting family planning client needs at the local level. In addition, integration of family planning into other maternal and child health services is the norm.

\section{Conclusions}


The coordination and integration of family planning across both providers and services may help explain the extraordinary increase in Rwanda's contraceptive usage, and has potential applications for enhancing family planning service delivery in other settings as well.

Keywords: Rwanda, family planning, integration, community health worker, coordinated services

\section{Background}

The Alma Alta Declaration highlighted the urgent need for all persons to have access to primary care in order to meet basic human rights to health and to achieve poverty alleviation (1). One route to increasing access to primary care for all persons, particularly for populations hardest to reach, is via community health worker (CHW) programs (2). CHW programs provide primary comprehensive healthcare in the community (3), and extant research shows that the most effective programs have CHWs who are elected members of the communities that they serve (2). Despite some challenges identified in sustaining $\mathrm{CHW}$ programs, research thus far suggests that $\mathrm{CHWs}$ are a worthy investment for public health $(1,4)$.

Health systems must be strong in order to increase access to primary health care (5). Health systems are strengthened via effective linkage between $\mathrm{CHWs}$ and the next level of service, an awareness of service roles, and referral patterns $(1,6)$. Unfortunately, this is not always the case, as relationships between the formal health care system and CHWs are often strained $(2,4)$.

CHWs are trained to provide a broad range of health services in the community, and in people's homes. Family planning is one of those important services (7). Family planning (FP) use reduces maternal death via a reduction in the number of unintended pregnancies, and helps prevent high-risk pregnancies such as those associated with young or old age, high parity, and short inter-pregnancy intervals. Over the past two decades, FP use in developing countries has reduced the number of maternal deaths by $40 \%$. Another $30 \%$ of maternal deaths could be averted if all contraceptive needs across the globe were met (8). The reach of FP programs depends upon an existing well-functioning health delivery system (5). CHW programs can extend the reach of FP programs through increasing community access - an integral component of FP program success (9). There are some examples of CHW programs increasing FP access $(7,10)$. Another route to expanding access to FP is via the integration of FP into other health services. There is accumulating evidence of successful FP integration into existing health services, including HIV care $(11,12)$, maternal care (13), and child health (14).

\section{The Rwandan context}

Rwanda has achieved great success in increasing contraceptive use: the usage rate among currently married women tripled from 17 percent in 2005 to 52 percent in 2010 (15). Rwanda's government involvement is critical in the inception, design, and support of the family planning program in Rwanda (16-19), as well as building health care infrastructure to reach such a wide breadth of Rwanda's population (20). 
The Government of Rwanda used inspiration from the Alma Alta of 1978 to provide primary health care to all of its citizens (21). To facilitate community ownership, and to address health care worker shortages, the Government of Rwanda initiated a CHW program in 1995. CHWs provide a number of health services to individuals in their communities, including FP, as the Rwandan Government recognizes the role of FP use in development (17). CHWs serve as the first point of contact for Rwandans seeking FP services and they connect people with the next tier of health care provider for continued care of the client's needs (22). CHWs also provide FP information to clients when providing other services as a method of FP outreach. Given Rwanda's rapid increase in FP use, this research aimed to investigate the role of coordinated and integrated FP service delivery in Rwanda from the perspective of FP providers and users.

\section{Methods}

Data used in this research were collected in two districts in Rwanda in two phases in 2018. The two districts selected were Musanze and Nyamasheke as they correspond to the districts with the highest and lowest rates of modern contraceptive usage in Rwanda, respectively (15). The first phase included eight focus group discussions with FP providers, four with FP nurses and four with Community Health Workers (CHW), in February 2018. FP providers were recruited via non-governmental organization and governmental staff intimate with the FP providers in the two districts. The second phase of data collection in July 2018 included 32 in-depth interviews with experienced female modern contraceptive users at least 18 years of age in the same two districts. The FP providers assisted us in recruiting the experienced FP users. Half of the focus group discussions and in-depth interviews were conducted in both Musanze and Nyamasheke.

Study participants signed informed consent forms in Kinyarwanda prior to participation. The moderators and note-takers, as well as the interviewers, were native Kinyarwanda speakers who used semi-structured topic guides to guide the data collection activities. The focus group discussions included between eight to 12 providers and lasted on average two hours while the in-depth interviews averaged 43 minutes in duration. Audio recordings were then translated into English and transcribed.

Data analysis was guided by content analysis (23). Transcripts were coded by theme using Atlas.ti 8 software (24). First, all researchers coded two transcripts independently. Second, the research team then collaboratively compiled a master code list that was used to code the remaining transcripts. Group-level matrices containing quotations from study participants were further analyzed using Microsoft Excel.

Approval to conduct this study was obtained from the Institutional Review Boards at Western Washington University as well from the Rwandan Ministry of Education prior to study participant recruitment.

\section{Results}

\section{Coordinated FP Service Delivery}


There is a high level of coordinated FP service delivery in Rwanda. This coordination is demonstrated through the complementary roles played by different provider types, nurses and $\mathrm{CHWs}$, as well as the awareness of these roles by community members.

\section{First Point of Contact: CHW}

Experienced contraceptive users in both Musanze and Nyamasheke agreed that the presence of CHWs has been a tremendous asset to their communities, since the presence of a CHW brings close access to a trained FP service provider and contraceptive methods. Data showed that women appreciate the improved access $\mathrm{CHWs}$ bring, as nearly $100 \%$ of respondents specifically raised this topic.

It is so easy to get the product that I need.... It's so easy, there are family planning providers close to home.

Female, injectables for 10 years, 50 years old, 5 children, limiter, Musanze

...I live near the community health workers so I have access to services in the way that I want and in the time that I want.

Female, injectables for 8 years, 31 years old, 3 children, spacer, Musanze

...the availability of contraceptives is everywhere...

Female, condoms, 41 years old, 5 children, spacer, Musanze

Women noted that $\mathrm{CHWs}$ also do home visits, sometimes even to deliver a desired contraceptive method.

Community health workers make things easier. Like, when I need a condom they bring it to my home.

Female, condom user for 2 years, 35 years old, 4 children, limiter, Nyamasheke

CHWs were not only easy to access in terms of proximity to the women's neighborhoods, they were also accessible as friends and confidants.

The community health workers care about us. Anytime we go they give us the services we need.

Female, injectable user for 6 years, 38 years old, 6 children, limiter, Musanze

The thing that the community health workers do to make things easier is making me feel comfortable. The community health worker is the person that you already know in the village, and there isn't anything you can be afraid of asking her because you already know each other. You can discuss anything.

Female, injectable user, 41 years, 5 children, limiter, Musanze

CHWs were noted as the first point of contact for community members interested in using family planning for information, resupply of methods, or to discuss issues they might have with method use. 
CHWs were the primary contacts for women due to proximity but also rapport.

Now it is easy to get contraceptives because you can find it everywhere in your village. Before the CHWs began, you had to go all the way to the health center, but now it is easier because there is someone who can give it to you in the village.

CHW, female, 50 years old, 6 children, implant user, Musanze

We're neighbors with the community health workers, so if I have a problem I'll go to the community health workers...

Female, condoms, 41 years old, 5 children, spacer, Musanze

The community health workers are valuable people. They are the ones who are closest with the clients. Because any problem that a client meets, they directly go to see the community health workers.

Nurse, female, 50 years old, 3 children, IUD user, Nyamasheke

\section{CHW Refers Client to Health Center}

Women and CHWs often discussed how the CHWs would connect clients with health centers and professional providers. At the clinic, every health provider has been trained in family planning service delivery.

The other thing I can say the country helped us in is that at the health center every nurse is capable to give family planning methods. This means that they trained us about family planning. Every hospital staff knows how to give family planning methods.

Nurse, female, 35 years old, 4 children, injectable user, Nyamasheke

The CHW will attend to the woman, and if the issues extend beyond the capacity of the CHW, then the $\mathrm{CHW}$ refers the woman to the nearest health center for assistance.

If they (CHWs) are met with a problem that is higher than their level of knowledge, they send the women to the health center.

Female, pill user for 3 years, 45 years old, 2 children, spacer, Nyamasheke

Sometimes $\mathrm{CHWs}$ even accompany the client to their health center appointment to increase the client's comfort in finding the right location and to help with communication.

If I have a problem I go to the community health worker first, and if she can't resolve my problem she can accompany me to the health center because I may be shy or don't know where to go. 
Female, condoms, 41 years old, 5 children, spacer, Musanze

Problems women faced could include the need to test for pregnancy before resupply of contraceptive methods.

...the contraceptive pills lasts between two and three months, and every three months we have to go to the provider to get more. Before they give you the pills they talk with you and ask if you are good at taking them on time, and you explain your experience. And if there is a time where you may have forgotten to take the pill, she will tell you that she can't give you more pills yet because you may be pregnant. She will tell you to go to the health center first to make sure you aren't pregnant and that things are okay, and then you can come back and get the pills from the nurse.

Female, pill user for 10 years, 38 years old, 3 children, limiter, Musanze

CHWs would transfer women to the health center for testing prior to initiation of contraceptive use or if the needed assistance in allevation of unmanageable side effects.

\section{Medical Tests at the Health Center}

A theme present in nearly all focus groups and some interviews was the requirement for new clients to undergo medical testing at health centers prior to initiating contraceptive method use. The test results may indicate contraindication of some methods for the client. CHWs do not conduct these tests themselves, as they are only done at health centers. Rather, $\mathrm{CHWs}$ counsel new clients on methods, but do not initiate method use until medical tests are complete.

Even though as $\mathrm{CHWs}$ we teach her about different methods, we do not have the approval to give her those contraceptives. At that time we will give her a transfer to the health center. At the health center they will take some test in order to get a suitable method for her.

CHW, male, 49 years old, 4 children, injectable user, Nyamasheke

The tests that providers implement may include pregnancy tests to rule out pregnancy prior to contraceptive use initiation. Providers might also test for pre-existing health conditions, such as high blood pressure, which may indicate that an individual is not eligible for certain contraceptive methods.

First, you have to go to the health centers where you get all the tests before they give you the method you want. Tests to check that you are not pregnant or that you don't have high blood pressure and other problems.

Female, former implant user, 38 years, 5 children, limiter, Nyamasheke

Nurses at health centers also use tests to check on the health of sustained users at periodic intervals. 
At health centers sometimes they test our weight to see whether after getting that method our weight is increasing or decreasing, and also our blood pressure to see whether the pressure is high so if they see that they can advise you to switch to another method. You can see that they are caring for us.

Female, pills for 4 years, 32 years old, 3 children, limiter, Musanze

\section{Nurses Transfer Client Back to CHW}

Once "cleared" by the nurses to begin using contraception, women are transferred back to the CHWs for method resupply if they elected to use condoms, pills, or injectables.

...I have first to go to the health center. After getting tests and my method they give me ordinance and I give that ordinance to the community health workers as proof that I have already gone to seek out family planning so that they can continue to look after me.

Female, injectable user for 6 years, 32 years old, 2 children, spacer, Nyamasheke

CHWs also reconnect with clients after visits to the health centers to make sure they received the services they needed, discern how satisfied they are with their selected contraceptive method, and to remind the client to visit them if any issues arise.

You have to see her again after she gets back from the health center to discuss with her. I would tell her that if she has some changes in her body she should come back to see me, because this may happen.

CHW, female, 47 years old, 4 children, pill user, Musanze

Most importantly, participants were aware of what cadre of provider could help them obtain the method they desired. Participants, regardless of method used, knew that they needed to go to a health center for long term or permanent methods, while they could access short-term methods from the CHWs, only for resupply. Study participants noted the increased efficiency of the coordinated service delivery model.

Due to a lot of women that want services of family planning, there is a program that has started, some have been oriented to health centers, and others to community health workers, in order to reduce the lines of women that were waiting for the services. And also as a way to increase the services going fast for each woman that needs the services.

Female, pills for 4 years, 32 years old, 3 children, limiter, Musanze

\section{Coordinated Integration of FP During Antenatal and Postnatal Care}


Within the system of coordinated FP service delivery, integrating FP into prenatal and postnatal care is a natural extension of the current system. CHWs and nurses teach women seeking prenatal care about FP so the women are informed about their options and have time to process the information with their husbands and others prior to birth. In some cases, women decide to initiate method use immediately after birth, and the health center is prepared to fulfill that desire. For others, women wait to initiate FP use until later in the postpartum period.

When someone is pregnant, in her 15th week of pregnancy, she has to go to the hospital to check if her baby is growing so at that time they get information...the doctor discusses with her about different contraceptive methods.

Nurse, female, 36 years old, 1 child, implant, Nyamasheke

After they give her the information she needs, the $\mathrm{CHW}$ will send her to the doctor and the doctor before sending her into labor will find a method for her to use because she asked for it. He will find a method before sending her home, because she can get pregnant in those six months after birth.

CHW, female, 44 years old, 5 children, pill user, Musanze

CHWs also check on postpartum women who have not yet begun using contraceptives. This helps ensure that FP needs do not go unmet.

After giving birth, the $\mathrm{CHW}$ will continue to take care of her and further explain why using contraception is important...

CHW, female, 48 years old, 6 children, condom user, Nyamasheke

I first learned about family planning from nurses when I was going to get tests at the hospital during my first pregnancy. And then, I also learned about it when I had my first birth because here, when a woman gives birth, the community health workers visit her and give advice on how to use family planning.

Female, former injectable user, 32 years, 3 children, spacer, Musanze

At health centers when a woman is going to seek other services, they remind her that the family program is there, also after having her first child, the community health workers and nurses remind her that she has to choose methods in order to put space between her first child and her next children.

Female, pills for 4 years, 32 years old, 3 children, limiter, Musanze

...here in Rwanda women who are pregnant always have a CHW who checks in on how she is doing. So, in the discussion I have when I come to see how her pregnancy is, I would advise her about how to use family planning after giving birth and help her to choose the method that she wants to use.

CHW, female, 43 years old, 3 children, injectable user, Musanze 


\section{Timing of Integration}

A sequence of FP integration arose often: women were informed about FP methods during pregnancy and initiated contraception during child health visits - particularly child vaccinations and weight checks. Spacing was commonly cited as the reason for FP use.

...I first understood about family planning when I was going to get a pregnancy test when I was pregnant my first time. After getting those tests, they teach us about how a woman can use family planning programs in order to help children so they aren't close in age in order to have a healthy life and to raise children well. They try to tell us about all methods and at that time when I go back home I discussed it with my husband. After agreeing with my husband is when we decided to use family planning after having our first kid. After giving birth, like one month, I go to the kid's vaccination and they give me that method of family planning.

Female, former implant user, 36 years, 3 children, spacer, Nyamasheke

....at that time that I came to get vaccination for my children I learned that contraception was a good thing and it helps a family in general in Rwanda, and that's what caused me to start using contraceptives.

Female, sterilized, 40 years, 9 children, limiter, Nyamasheke

The Community Health Worker will continue the vaccines with those children and will also continue telling her about family planning.

Nurse, female, 34 years old, 2 children, implant, Musanze

...I was going to the health center getting some tests for my first child when the nurses reminded us that the family planning program was also there...

Female, injectable user for 6 years, 32 years old, 2 children, spacer, Nyamasheke

\section{Discussion}

Both FP providers and experienced FP users in both districts noted that FP service delivery in Rwanda is well coordinated. $\mathrm{CHWs}$ in the communities and nurses at health centers occupy complementary roles to ensure easy access to contraception for women based upon their individual needs. A longitudinal study on fertility and FP use in Ghana noted that the combined efforts of FP providers and volunteers in FP program promotion resulted in the greatest fertility reduction (7). Other researchers have also noted the important role of community based FP distribution in FP use (25). Rwanda's highly efficient service delivery system makes integration of FP into other services possible - such as antenatal, postpartum, and child health services, especially when the target population of the two services aligns so well. The persistent inclusion of FP information at relevant check-ups with health care professionals appears to be highly effective. 
It is clear that CHWs are vital members of this efficient and integrated system. As described by the women interviewed, the $\mathrm{CHW}$ program in Rwanda is working well for them in terms of increasing access to information and services at their doorsteps. CHW programs have been implemented in many different nations around the world with varying degrees of success (2). A number of characteristics of the Rwandan CHW program arose in this research that have been considered integral to successful CHW programs in the literature: $\mathrm{CHWs}$ live in and are selected by their neighbors for their role, they have frequent interactions with and are well-respected by members of their communities - which serves as the most important method of supervision, and the links between $\mathrm{CHWs}$ and the formal health sector is strong $(2,3,6,26)$. The success of the Rwandan CHW program could ultimately be due to government support and respect of $\mathrm{CHWs}$ that sets up the pathways associated with successful CHW programs $(22,26)$.

Since $\mathrm{CHWs}$ provide a range of services to their fellow community members, in addition to FP, the $\mathrm{CHW}$ design naturally allows for easy integration of one service into another. The "one-stop-shop" model for integration, where many different health care services can be administered at the same time and space, has been shown to increase cost efficacy in Kenya, and was generally linked to higher levels of modern method contraceptive use and knowledge among women with HIV (12). The absence of transportation time and cost with CHWs amplifies the "one-stop-shop" integration experience. In addition, the strong linkage between $\mathrm{CHWs}$ and the formal health system enforces the integration of FP into other health services - as does the training of all formal health system staff in FP.

This research highlights that the combination of well-coordinated service delivery and integration of FP has been critical in Rwanda's family planning success. Yet, integration in Rwanda has not reached its full potential. Since there is a large focus on women's fertility within marriage in Rwanda, unmarried women and adolescents are often less exposed to FP discussions and are not encouraged to use FP as strongly as married women who have already had at least one child. The Adolescent Sexual and Reproductive Health and Rights (ASRH\&R) Policy of 2011 notes the lack of youth friendly facilities and emphasizes the importance of providing FP counseling and advice to adolescents. It also mentions the need for an adolescent-specific health facilities referral system (17). Thus, integration of FP information into settings in which adolescents, unmarried, or previously married women may have more access to may be helpful in reaching these populations. Additionally, research and programs should explore the extent to which FP integration is possible for all person years prior to a woman's first pregnancy.

This study has a number of strengths. The qualitative methods utilized allows for deeper inquiry into the topics, and the triangulation of findings between FP providers and FP users provides an exploration of the topic from multiple perspectives. The data were collected in two districts purposively selected for having the highest and lowest contraceptive use rates in the nation as a reliability check. Despite the study strengths, the study does suffer from a few limitations. Due to the qualitative nature of the study the findings are not generalizable. In addition, using FP providers to assist in recruitment of experienced FP users may have biased our sample to more experienced and satisfied contraceptive users. 


\section{Conclusion}

Rwanda's increase in contraceptive rates over the past two decades has been astounding. While wellcoordinated FP service delivery and FP integration into general health care has been helpful in spreading awareness and usage of FP methods, the success of Rwanda's FP program extends far beyond information integration and community-based infrastructure, and elicits continued investigation. Yet, wellcoordinated FP service delivery integration, as implemented in Rwanda, introduces a viable strategy for other countries to expand FP use, and sheds light on a potential path to a promising future for FP programs throughout the world.

\section{List Of Abbreviations}

$\mathrm{CHW}=$ community health worker

$\mathrm{FP}=$ family planning

\section{Declarations}

\section{Ethics Approval and Consent to Participate}

This study was reviewed and approved by the Western Washington University Ethics Committee as well as the Rwandan Ministry of Education Ethics Committee. All study participants consented to study participation prior to participating in the study.

\section{Consent for Publication}

Not applicable

\section{Availability of Data and Materials}

The data generated and analyzed during the current study are available from the corresponding author on reasonable request.

\section{Competing Interests}

The authors declare that they have no competing interests.

\section{Funding}


This study was funded by the National Science Foundation. The National Science Foundation had no role in the design of the study, data collection, analysis, nor interpretation of the data or writing of the manuscript.

\section{Authors' Contributions}

HMS designed the study. All authors participated in data collection, analysis, and interpretation of the data. All authors approve the final version of this paper.

\section{Acknowledgements}

The authors wish to acknowledge Dean Faustin Habineza of INES for his roll in facilitating this international research collaboration.

\section{References}

1. Rohde J, Cousens S, Chopra M, Tangcharoensathien V, Black R, Bhutta ZA, et al. 30 years after AlmaAta: has primary health care worked in countries? The Lancet. 2008 Sep;372(9642):950-61.

2. de Vries DH, Pool R. The Influence of Community Health Resources on Effectiveness and Sustainability of Community and Lay Health Worker Programs in Lower-Income Countries: A Systematic Review. Yi H, editor. PLoS ONE. 2017 Jan 17;12(1):e0170217.

3. van Ginneken N, Lewin S, Berridge V. The emergence of community health worker programmes in the late apartheid era in South Africa: An historical analysis. Social Science \& Medicine. 2010 Sep;71(6):1110-8.

4. Lehmann U, Sanders D. Community health workers: What do we know about them? The state of the evidence on programmes, activities, costs and impact on health outcomes of using community health workers. World Health Organization; 2007.

5. Travis P, Bennett S, Haines A, Pang T, Bhutta Z, Hyder AA, et al. Overcoming health-systems constraints to achieve the Millennium Development Goals. The Lancet. 2004 Sep;364(9437):900-6.

6. Witmer A, Seifer SD, Finocchio L, Leslie J, O'Neil EH. Community health workers: integral members of the health care work force. Am J Public Health. 1995 Aug;85(8_Pt_1):1055-8.

7. Debpuur C, Phillips JF, Jackson EF, Nazzar A, Ngom P, Binka FN. The Impact of the Navrongo Project on Contraceptive Knowledge and Use, Reproductive Preferences, and Fertility. Studies in Family Planning. 2002;33(2):141-64. 
8. Cleland J, Conde-Agudelo A, Peterson H, Ross J, Tsui A. Contraception and health. The Lancet. 2012;380(9837):149-156.

9. Mwaikambo L, Speizer IS, Schurmann A, Morgan G, Fikree F. What works in family planning interventions: A systematic review of the evidence. 2013;51.

10. Douthwaite M, Ward P. Increasing contraceptive use in rural Pakistan: an evaluation of the Lady Health Worker Programme. Health Policy and Planning. 2005 Mar 1;20(2):117-23.

11. Grossman D, Onono M, Newmann SJ, Blat C, Bukusi EA, Shade SB, et al. Integration of family planning services into HIV care and treatment in Kenya: a cluster-randomized trial. AIDS. 2013 Oct;27:S77.

12. Haberlen SA, Narasimhan M, Beres LK, Kennedy CE. Integration of Family Planning Services into HIV Care and Treatment Services: A Systematic Review. Studies in Family Planning. 2017;48(2):153-77.

13. Baqui AH, Ahmed S, Begum N, Khanam R, Mohan D, Harrison M, et al. Impact of integrating a postpartum family planning program into a community-based maternal and newborn health program on birth spacing and preterm birth in rural Bangladesh. J Glob Health [Internet]. 2018 [cited 2019 May 21];8(2). Available from: https://www.ncbi.nlm.nih.gov/pmc/articles/PMC6036944/

14. Huntington D, Aplogan A. The Integration of Family Planning and Childhood Immunization Services in Togo. Studies in Family Planning. 1994 May;25(3):176.

15. National Institute of Statistics of Rwanda, Ministry of Finance and Economic Planning, Ministry of Health, The DHS Program, ICF International. Rwanda Demographic and Health Survey, 2014-15: Final Report. Kigali, Rwanda: Rockville, Maryland, USA; 2016. 615 p.

16. Republic of Rwanda, Ministry of Finance and Economic Planning. Rwanda Vision 2020 [Internet]. Kigali (Rwanda): The Ministry; 2000. Available from: http://www.sida.se/globalassets/global/ countriesand-regions/africa/rwanda/d402331a.pdf

17. Republic of Rwanda, Ministry of Health. Family Planning Policy [Internet]. Kigali (Rwanda): The Ministry; 2012 [cited 2017 Jun 22]. Available from:

http://www.moh.gov.rw/fileadmin/templates/Docs/Rwanda-Family-Planning-Policy.pdf

18. Schwandt HM, Feinberg S, Akotiah A, Douville TY, Gardner EV, Imbabazi C, et al. "Family planning in Rwanda is not seen as population control, but rather as a way to empower the people": examining Rwanda's success in family planning from the perspective of public and private stakeholders. Contraception and Reproductive Medicine [Internet]. 2018 Dec [cited 2019 Jan 29];3(1). Available from: https://contraceptionmedicine.biomedcentral.com/articles/10.1186/s40834-018-0072-y

19. Solo J. Family Planning in Rwanda: How a Taboo Topic Became Priority Number One. Chapel Hill, NC, USA: IntraHealth; 2008 Jun. 
20. Langston A, Weiss J, Landegger J, Pullum T, Morrow M, Kabadege M, et al. Plausible role for CHW peer support groups in increasing care-seeking in an integrated community case management project in Rwanda: a mixed methods evaluation. Global Health: Science and Practice. 2014 Aug 1;2(3):342-54.

21. WHO. Declaration of Alma-Ata [Internet]. 1978 [cited 2019 May 29]. Available from: http://www.who.int/hpr/NPH/docs/declaration_almaata.pdf

22. Ministry of Health, Rwanda. National Community Health Policy. 2015.

23. Green J, Thorogood N. Qualitative Methods for Health Research. Thousand Oaks: Sage; 2004.

24. Atlas.ti. Berlin: Scientific Software Development; 1993.

25. Nyonator FK, Awoonor-Williams JK, Phillips JF, Jones TC, Miller RA. The Ghana Community-based Health Planning and Services Initiative for scaling up service delivery innovation. Health Policy and Planning. 2005 Jan 1;20(1):25-34.

26. Rosato M, Laverack G, Grabman LH, Tripathy P, Nair N, Mwansambo C, et al. Community participation: lessons for maternal, newborn, and child health. The Lancet. 2008 Sep;372(9642):962-71. 